\title{
Automated robot-based charging system for electric vehicles
}

Bernhard Walzel*, Christopher Sturm, Jürgen Fabian, Mario Hirz Institute of Automotive Engineering 


\begin{abstract}
With the rising number of electric and hybrid vehicles the demand for customerfriendly and innovative solutions for the charging infrastructure is growing steadily. Furthermore, future autonomous driving and parking vehicles are calling for new approaches regarding to battery charging. Nowadays electric vehicles have to be charged by hand. In other words, someone has to connect the charging cable with the charging socket of the vehicle. This paper deals with automated charging systems for electric vehicles. In order to realize tethered charging a fully automated system supports the complete process. The first part of work explains advantages of automated conductive charging systems regarding to other automated concepts and why such systems are needed. The second part deals with an investigation of the state of art. Thereby it is evidenced which systems are already developed and published. Afterwards, challenges and problems behind automated conductive systems are shown. Thereby the individual problems are analysed and illustrated. Finally, an initial concept for automated charging station is presented and discussed as a solution charging multiple and various types of vehicles at public parking facilities.
\end{abstract}




\section{Introduction}

Besides the limited range of electric vehicles in comparison to conventional powered vehicles, one additional drawback is the time consuming and laborious charging process. To enable comfortable and autonomous battery charging lot development effort is invested in inductive charging systems. Due to the advantages of the contactless method, manufactures are working on the marketability of this technique. But several challenges like energy losses, electromagnetic radiation, complex vehicle adaption or environmental impacts on humans and animals still have to be solved. Furthermore, long driving ranges together with short charging intervals are essential for a high customer benefit. Due to a significantly lower power transmission performance, high charging capacities are not feasible with inductive systems, but only with conductive systems (DC quick or fast charging). Battery switch stations provide another option. Because of the high investment costs as well as the difficult grid and vehicle integration these techniques will be not discussed further here. Figure 1 depicts how many kilometres per hour loading capacity can be covered depending on the loading method $[1,2]$ and based on the energy consumption of an average electric vehicle [3]. In this comparison, charge and discharge losses are not considered. As shown fast charging technologies with loading capacities up to $170 \mathrm{~kW}$ [2] reduce the charging time significantly in comparison to low charging methods.

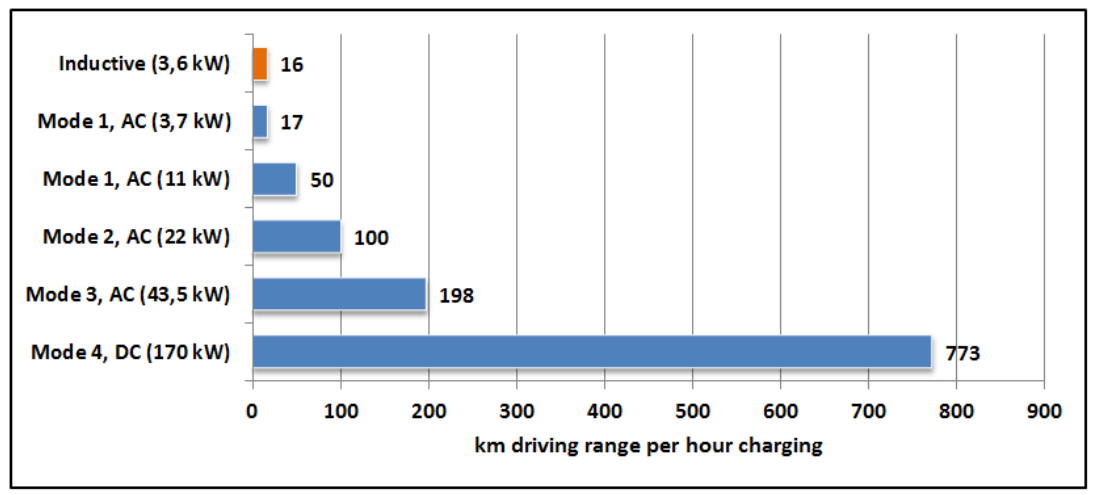

Figure 1: Charging capacity by charging method

In order to realize powerful DC charging currents the wire diameter must grow. This in turn makes the cable heavy, stiff and unhandily, so that people might have problems to charge their vehicle [4]. This possibility to load vehicles as user friendly as 
possible is one reason why automated conductive charging systems are getting increasingly interesting.

Autonomous vehicles together with automated charging systems offer new opportunities. Fully automated park and charging solutions enable customer-friendly and innovative service concepts. For example, driver parks in front of shopping centres: The car drives to the next free parking lot autonomously, charges the batteries automatically and picks up the driver after the shopping tour by a call via mobile phone app. Volkswagen works already on the realization of similar projects with automated cars and inductive charging systems [5].

\section{State of the art}

Automated charging systems are in development this time, but no manufacturer has launched a series product on the market until now. Furthermore, every current published system is only customized for one specific vehicle model. That means that only that specific model can be charged. In future years an automated system should be able to charge every electric vehicle independent from the car type.

\subsection{Volkswagen e-smartConnect}

The manufacturer VW recently presented such a system for an e-Golf, as a research facility in the test phase. The project, shown in Figure 2, is called e-smartConnect and is based on a KUKA LBR iiwa, a Robot of the newest generation. The DC quick charging process starts with a communication between vehicle and electric filling station. The vehicle transmits its data to the charging station, which transmits in return the target position for the automated parking. The charging socket of the vehicle has to be in a target area of 20 by 20 centimetres. Afterwards, a camera on the robot detects the exact position of the charging socket, which is accurately defined to a millimetre. Following, the robot-gripper picks the DC-Connector and links it with the charging socket of the vehicle. After having linked the DC-Connector, the charging process starts. Once the battery is fully charged, the robot automatically unplugs the DC-Connector [6]. 


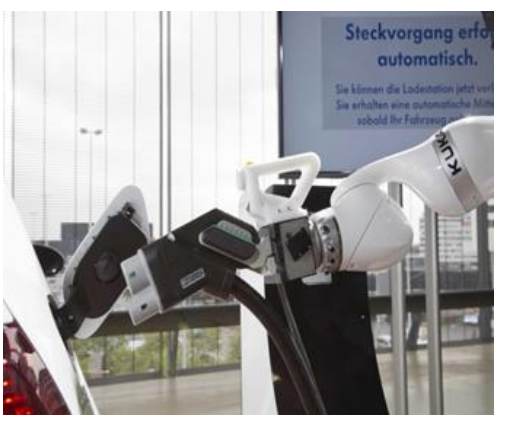

Figure 2: VW e-smartConnect [6]

\subsection{Tesla charging-robot}

The US Company Tesla also works on an automated system (Figure 3). Their concept is even based on DC current and should load their on-site vehicles. The charging cover opens automatically when the parked vehicle is ready for loading. The system detects this and afterwards the snakelike prototype robot arm is searching its way to the charging socket fully autonomously. Once the connection between the robot and the vehicle is made, the charging process can be started. The idea behind the concept is, that the driver does not have to get out of the car to charge the vehicle. The complete loading procedure is applied by the robot. How the robot finds its target and detailed technical information about the charging system are not published yet. In general, the system is currently in a prototype status this time. A benefit of Tesla is that all their cars have the same position of the charging socket and also the same charging plugs [7].

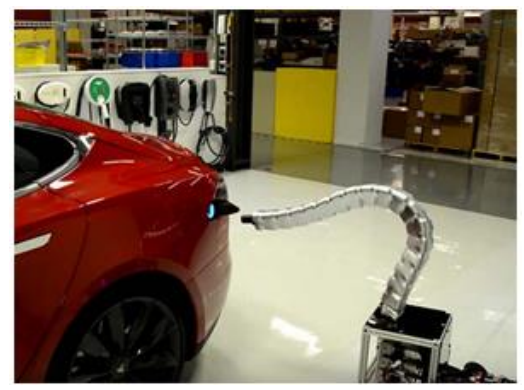

Figure 3: Tesla charging robot [7] 


\subsection{Charging system TU-Dortmund}

The Technical University of Dortmund started a project named ALanE. The acronym stands for automated charging system for sustainable electric mobility (Figure 4). The aim of the project is to charge a parked electric vehicle without needing the driver to plug in the charging cable. A manual intervention of the driver is not necessary. Thus, in comparison to established charging systems, the ALanE system raises the comfort enormously, which represents itself as a unique selling point in comparison to conventional powered vehicles. The charging system of the TU Dortmund contains a standard energy supply and a wallbox, which is extended with a cost-effective and compact connection module (VBM). The connection and disconnection process can be started via a smartphone app. This system is also in a prototype status yet and under further development [8].

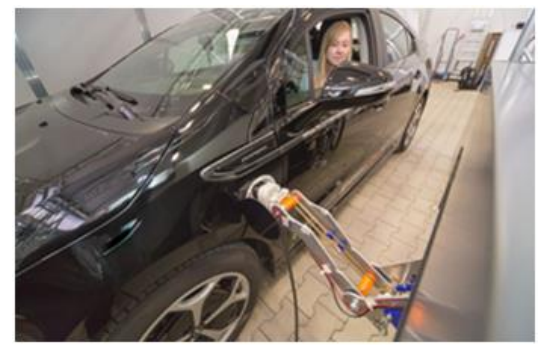

Figure 4: Charging robot TU-Dortmund [8]

\subsection{Charging system NRG-X}

The NRG-X concept represents itself as the first fully automatic charging solution. The fundamental idea was to create a system, which transfers high power energy for fast charging, enables a great range of parking tolerance and substitutes an expensive conventional wallbox. Additionally, it can be easily adapted to every electric vehicle. The system shown in Figure 5 contains two basic components, a connection array, which is mounted in the middle of the car underbody and a base station, which represents the connection system at the parking area.

The surface of the connection array is consistently structured by a hexagonal pattern, whereas each cell has a conical shaped recess. The base station, which constitutes the counterpart, slides into any cell by an orthogonal movement towards the connection array. This means, any arbitrary position of the cone within the dimensions of the 
connecting array reaches a discrete final position in the middle of the respective contacting cell. The positioning cone must be resilient and therefore laterally (in $\mathrm{x}-$ and $\mathrm{y}$ direction) moveable for the distance of a contacting cell outer radius.

The hole charging process is quite simple: When an electric vehicle, which is adapted with the NRG-X connection array, approaches to a garage or parking space, the NRG-X base station automatically starts to communicate with the connection array. The only requirement is that the electric vehicle must contain a wireless module. It is not necessary to park the vehicle in an exact predefined position. A position validation system ensures the correct position where an automatic connection is feasible. After the system checked the authorization and the batteries state of charge, the charging process starts automatically. The NRG-X base station lifted upwards to the connection array of the car underbody and connects the system. Possible charging power reaches up to $22 \mathrm{~kW}$. The charging process starts automatically when a secure connection is enabled or can be scheduled manually or by an intelligent charging management system. If the battery is completely full, the connection system disconnects immediately and automatically. In a further expansion stage, direct current quick charging should be realized above $>100 \mathrm{~kW}[9]$.

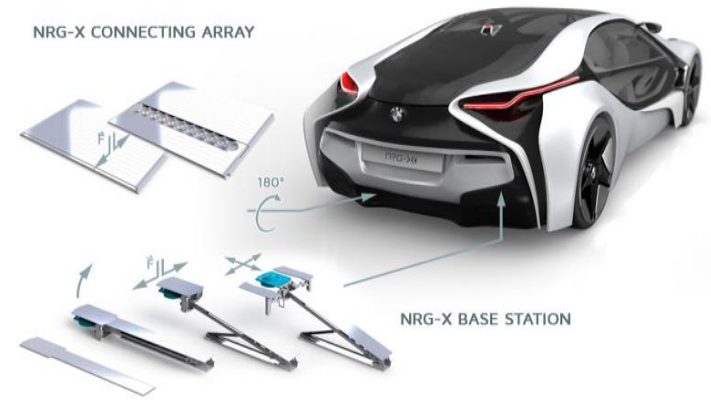

Figure 5: NRG-X [9]

\section{Problem areas}

The main idea of automated charging systems includes a very easy and comfortable charging process. The car parks in the parking bay and the remaining steps are being 
finished by the system automatically. That means the automated charging system detects the type and model of car, recognises thereupon the position of the charging socket, the required charging cable and charging strategy and starts afterwards with the charging process. As soon as the process is finished, the system picks up the charging cable and the vehicle is ready to drive. But there are some obstacles that need to be adjusted in order to realize automated conductive charging. From a purely technical point of view, such systems seem to be state of the art, but there are some challenges that must be solved - and for the target to handle different vehicle types, the challenges are rising significantly.

There is no standard for the position of the charging socket. An investigation of various vehicle types shows big differences regarding the socket places depending on the car brand and type. Electric and hybrid vehicles usually have their sockets on the right or left side, additionally some cars have it on the front or back side of the vehicle. Furthermore, the height of the socket is also different. There is a European standard for charging cables, the Type 2 (Mennekes) connector, but many manufacturers, especially in Asia or USA use other connector types.

A second big problem can be found in the charging cap mechanism. Several vehicles have a security cap that makes it impossible to charge the vehicle without removing them. Even in this field there are differences. Some brands have a rubber plug which has to be unscrewed, others have a plastic flap. The variety of the systems is often simply based on specific design solutions.

The target to charge multiple vehicles and different vehicle types at parking facilities requires complex devices for handling and management of cables, especially by the use of DC quick charging. Long and heavy cables with limited bend radius waste a lot of space and additionally, if they are not carried by the robot, separate logistic equipment is needed. For example, the weight of a CCS-Type 2 charging cable for charging capacities of up to $106,25 \mathrm{~kW}$ is $1,7 \mathrm{~kg} / \mathrm{m}$ and it has an outer diameter of $28,2 \mathrm{~mm}$ [10].

An overview about various vehicles types, charging sockets, plugs and security systems is presented in Figure 6 and 7. Figure 8 shows a typical parking situation of vehicles including the resulting charging socket position. As mentioned, these varieties of systems and vehicle-specific requirements complicate an automation of the charging process enormously. 


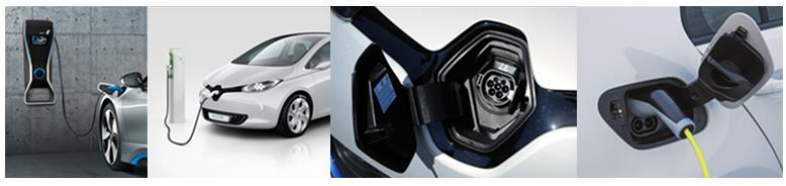

\begin{tabular}{cccccc} 
Brand & Typ & $\begin{array}{c}\text { Propulsion } \\
\text { System }\end{array}$ & Plug & Security Cap & $\begin{array}{c}\text { Max. Loading } \\
\text { Capacity }\end{array}$ \\
\hline Mercedes & $\begin{array}{c}\text { B-Klasse Electric } \\
\text { Drive }\end{array}$ & BEV & Typ 2 & plastic flap & $11 \mathrm{~kW}$ \\
KIA & Soul EV & BEV & Typ1/CHAdeMO & rubber plug & $50 \mathrm{~kW}$ \\
BMW & i8 & PHEV & Typ 2 & plastic flap & $4,6 \mathrm{~kW}$ \\
Renault & ZOE Q210 & BEV & Typ 2 & plastic flap & $43 \mathrm{~kW}$ \\
Peugeot & IOn & BEV & Typ 2 & plastic flap & $43 \mathrm{~kW}$ \\
Tesla & Model S & BEV & $\begin{array}{c}\text { Tesla } \\
\text { Supercharger }\end{array}$ & & $120 \mathrm{~kW}$ \\
Volkswagen & e-Golf & BEV & Typ 2/CCS & & $40 \mathrm{~kW}$
\end{tabular}

Figure 6: Examples for various vehicles types, charging sockets, plugs and security cap systems $[11,12,13]$

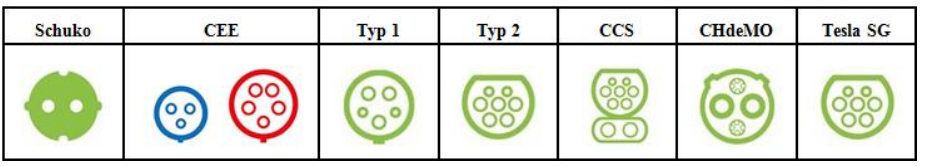

Figure 7: Cable connector types [14]

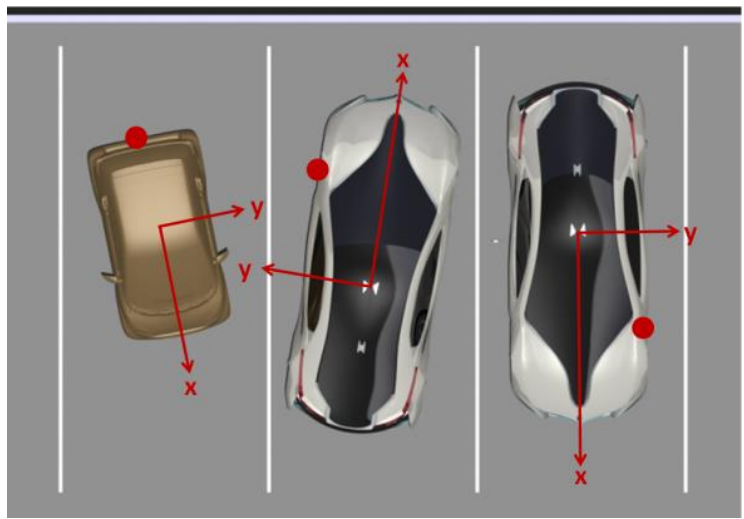

Figure 8: Vehicle positions in parking lots, resulting in different charging socket positions (red points) 


\section{Concept proposal}

As discussed in Section 2, several projects are already dealing with automated charging, but every concept either can charge only one specific car with one specific charging plug or is accompanied by costly vehicle adaptations. In this subsection, a concept for public parking facilities is introduced (Figure 9). The concept proposal is capable to charge any electric car independently from the brand, the charging socket position or the vehicle parking lot position and it does not require complex vehicle adaptions or modifications. Furthermore, it is possible to charge multiple vehicles with only one robot.

The basis of the concept is a lightweight collaborative robot that is mounted on a bridge crane-like system. This approach increases the range of motion for the robot significantly - every charging station spot is reachable and the number of cars is only limited by the length of the crane system. Safety plays an important role when using robots. Safety features of the robot allow people to be in the same working area as the robot and no safety fence is needed (collaborative robots). Force torque control enables well contact detection as a programmable resilience. Furthermore, the plug-in process is precise and force sensitive. Companies like Universal Robots or KUKA offer such robots $[15,16]$.

Every parking lot is equipped with a longitudinal movable and rotatable cable magazine, which travels closely to the charging socket before the charging process begins. This prevents sliding on the ground as well as difficult handling of heavy and long cables. With a universal gripper tool mounted on the robot arm, different types of charging plugs can be picked up from the cable magazine.

If a vehicle has to be charged, it parks in a free parking lot (manually or autonomously). For the next steps and for a successful charging process, the system must gather important data, including information of the already discussed variety of systems in the subsection problem areas. With wireless interconnectedness of vehicle, electric filling station, mobile phone and web servers, the charging process can be started or stopped as well as vehicle and charging strategy data can be transmitted and updated. The easy integration of billing and payment applications and storing and evaluation of the costumer charging behavior improves costumer benefit additionally. Figure 10 shows a proposal for the data communication and the data management of an automated electric filling station in public areas.

After the required information is transmitted, it is possible to control the charging process and the battery's state of charge. Meanwhile the vehicle is charging, the robot can serve other vehicles that also need to be charged. When the charging process is 
finished, the robot disconnects the cables and puts it back into the magazine and the whole process can start again from the beginning.

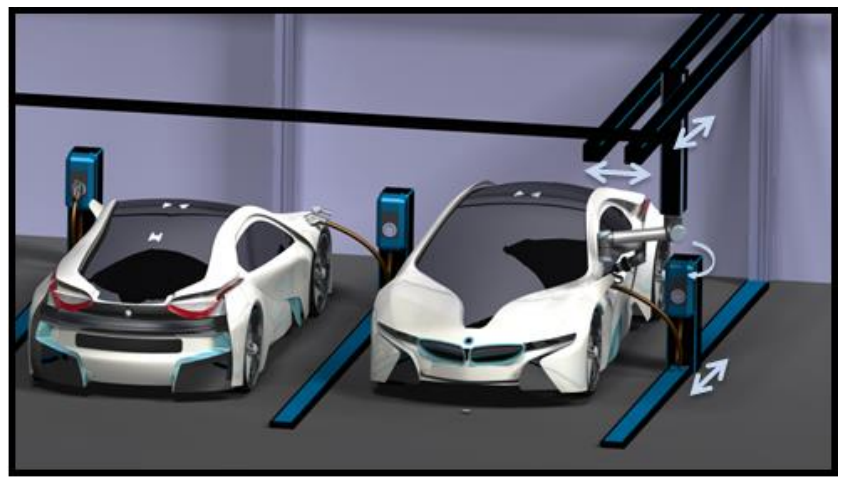

Figure 9: Proposal of an automated charging station for public areas

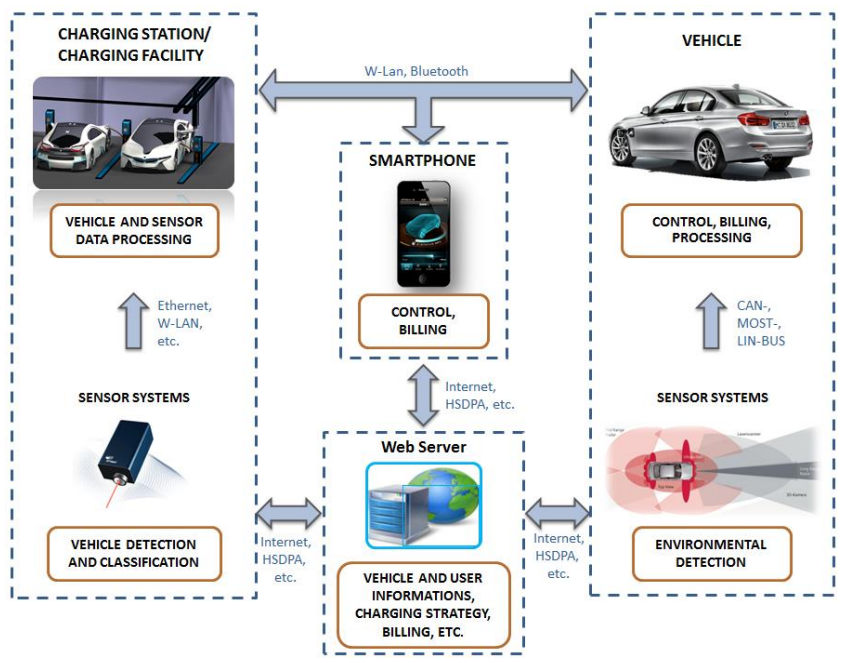

Figure 10: Data communication and data management proposal 


\section{Discussion and Outlook}

Conductive automated charging systems are a new emerging topic in the electric vehicle industry. By increasing charging power, the cables are getting more unwieldy and thereby charging of a vehicle can be very aggravating. Some pilot projects already employ with automatic charging systems, but currently they are all in a prototype status. The presented concept of an automated charging robot for parking garages gives an overview of possibilities for possible solutions. It considers the importance that every electric vehicle can be charged by one system. Furthermore, there are no modifications to the vehicle necessary. Future electric cars will be designed for automated charging. This includes barrier-free access to the charging socket or automated opening and closing systems of the loading covers and standardized communication systems. Inductive charging systems will be an alternative, but disadvantages like the limited charging capacity or unstandardized systems may restrict the application to private sector usage. Conductive automated charging systems include a high potential, whether in private or public sectors, to make charging of electric cars more comfortable. 


\section{References}

1. Haslauer (2012): 100\% Strom aus erneubaren Energien für E-Mobilität: Effekte Marktszenarien und Handlungsempfehlungen, Technische Universität Wien, Wien, 2012

2. Karle (2015): Elektromobilität Grundlagen und Praxis, Carl Hanser Verlag, 2015, ISBN: 978-3-446-44339-6

3. Geringer (2012): Batterielektrische Fahrzeuge in der Praxis: Kosten, Reichweite, Umwelt, Komfort, Wien, 2012

4. Springer Fachmedien (2015): e-smartConnect: Automatisches Aufladen mit Gleichstrom und Roboterassistenz, online: http://www.springerprofessional.de/esmartconnect-automatisches-aufladen-mit-gleichstrom-und-roboterassisten, accessed on 15. 9. 2015

5. Digital Trends (2015): VW combining automated valets and self-charging cars with the V-Charge project, online: http://www.digitaltrends.com/ cars/volkswagenv-charge-project-self-driving-cars-self-charging-cars-pictures, accessed on 15. 12. 2015

6. Autoblog BV (2015): Volkswagen e-smartConnect, online: http://www.autoblog.nl/imagegallery?file=Volkswagen/0_Divers/Volkswagen_e_s martConnect/Volkswagen-e-smartconnect-08.jpg, accessed on 16. 9.2015

7. Timebandit Media (2015): Mein Elektroauto, online: http://www.meinelektroauto.com/2015/08/tesla-motors-praesentiert-seinen-laderoboter-fuerelektroautos/18609, accessed on 16. 9.2015

8. Technische Universität Dortmund (2015): Ladesystem der TU-Dortmund ,betankt" Elektroautos automatisch, online: http://www.e-technik.tudortmund.de/cms1/de/Service_Termine/Weitere_Meldungen/Archiv/Ladesystem_ Elektroautos/index.html, accessed on 12.11. 2015

9. NRG-X (2015): NRG-X automatic charging solution, online: http://nrg-X.com, accessed on 13.11. 2015

10.Phoenix Contact (2016): Phoenix Contact products, online: https://www.phoenixcontact.com, accessed on 2. 1. 2016

11.BMW (2015): Der vollelektrische BMW i3, online: http://www.bmw.at/de/neufahrzeuge/bmw-i/i3/2013/start.html, accessed on 12. 8 . 2015 
12.Renault (2016): Renault ZOE, online: http://www.renault.at/neuwagen/zeelektrofahrzeuge/zoe/zoe/, accessed on 2. 1.2016

13.Sauer (2014): Volkswagen electrified! Woe fahren sich der VW e-Golf und Golf GTE, online: http://griin.de/serienreifes/volkswagen-electrified-fahrbericht-vw-egolf-und-golf-gte-teil-1, accessed on 6. 1. 2016

14. The Mobility House (2015): Welche Ladekabel zum Laden von Elektroautos gibts es?, online: http://mobilityhouse.com/de/ladekabelarten-und-steckertypen/, accessed on 6. 10. 2015

15.Universal Robots (2016): Universal Robots UR10, online: http://www.universalrobots.com/de/produkte/ur10-roboter/, accessed on 10.1.2016

16.KUKA (2016): KUKA LBR IIWA 14 R820, online: http://www.kukarobotics.com/austria/de/products/industrial_robots/sensitiv/lbr_iiwa_14_r820/start. htm, accessed on 2. 1. 2016 